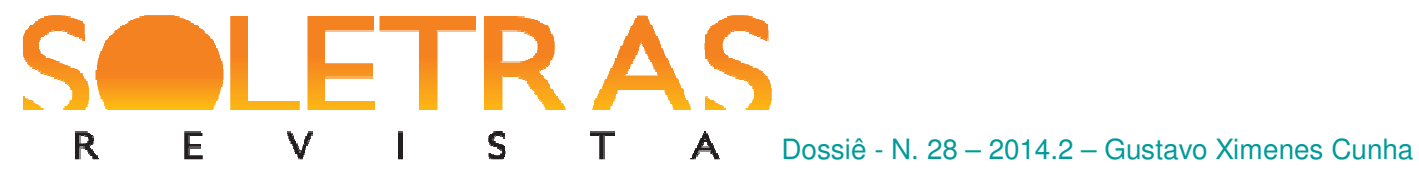

\title{
O estudo da articulação textual em diferentes perspectivas teóricas
}

Gustavo Ximenes Cunha ${ }^{1}$

Universidade Federal de Alfenas

\begin{abstract}
Resumo: Neste trabalho, proponho uma aproximação de dois modelos teóricos do texto/discurso: a Teoria da Estrutura Retórica e o Modelo de Análise Modular. Esses modelos surgiram em contextos bastante diferentes e apresentam finalidades diversas. Porém, considero que há entre eles pontos de convergência que podem ser bem explorados para se compreender melhor a complexidade da articulação textual. Com base na análise de uma introdução de um artigo científico, busco verificar em que medida esses modelos permitem estudos complementares da articulação textual. No que se refere às semelhanças, tanto a RST quanto o MAM oferecem ferramentas de análise adequadas para o estudo a macrossintaxe do discurso. Além disso, ambas se filiam à corrente mais ampla dos estudos pragmáticos, porque investigam as manobras discursivas que o produtor do texto realiza, a fim de provocar determinados efeitos de sentido junto ao interlocutor. Quanto às diferenças, cada abordagem dá atenção a determinados aspectos da articulação textual que, se forem levados em conta por ambas as abordagens, permitiriam que cada uma realizasse um estudo mais eficaz da articulação textual.
\end{abstract}

Palavras-chave: Articulação textual. Teoria da Estrutura Retórica do Texto. Modelo de Análise Modular do Discurso.

\section{Introdução}

Este trabalho propõe aproximar dois modelos teóricos do texto/discurso: a Teoria da Estrutura Retórica (Rhetorical Structure Theory - RST) e o Modelo de Análise Modular (Modèle d'Analyse Modulaire - MAM). O objetivo é verificar em que medida as ferramentas de análise desenvolvidas por esses modelos para o estudo da articulação textual são complementares. Embora esses modelos tenham surgido em contextos bastante diferentes e apresentem finalidades diversas, considero que há entre eles pontos de convergência que podem ser bem explorados para se compreender melhor a complexidade da articulação textual.

Desenvolvida a partir da década de 1980, na Universidade do Sul da Califórnia, nos Estados Unidos, por uma equipe de que fazem parte Mann, Thompson e Matthiessen, a RST

\footnotetext{
${ }^{1}$ Doutor em Linguística pela Universidade Federal de Minas Gerais (UFMG). Professor Adjunto do Instituto de Ciências Sociais Aplicadas (ICSA) e do Programa de Pós-Graduação em Gestão Pública e Sociedade (PPGPS) da Universidade Federal de Alfenas (UNIFAL-MG). E-mail: ximenescunha@ yahoo.com.br.
} 


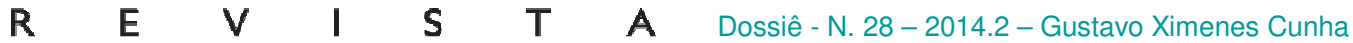

considera que a coerência de um texto resulta da função que cada constituinte desempenha em relação a outro. Assim, a RST busca caracterizar as relações retóricas ou proposições relacionais (elaboração, evidência, sequência, lista, concessão, etc) que emergem da combinação dos constituintes textuais. Nessa abordagem, a análise das relações retóricas de um texto se evidencia por meio da estrutura retórica.

Já o MAM se desenvolve, a partir do final da década de 1970, por uma equipe de pesquisadores da Universidade de Genebra, na Suíça. Nas diferentes etapas de seu desenvolvimento, o modelo foi sempre liderado por Roulet. O modelo modular é um instrumento que visa à compreensão da complexidade discursiva como um todo e que, por isso, também estuda a articulação textual. Esse estudo, como veremos adiante, se faz em duas etapas. Na primeira etapa, identificam-se as relações de discurso genéricas de uma produção discursiva. A identificação das relações genéricas se baseia em uma lista reduzida de categorias (argumento, contra-argumento, reformulação, comentário, etc). Nessa etapa, a análise das relações discursivas de um texto é representada por meio da estrutura hierárquicorelacional. $\mathrm{Na}$ segunda etapa, estuda-se a relação específica entre um constituinte em particular e uma informação da memória discursiva.

Para propor a aproximação dessas abordagens, utilizarei os instrumentos de análise das duas abordagens para estudar a parte introdutória de um artigo científico da área de Ciências Sociais Aplicadas, parte que reproduzo a seguir: ${ }^{2}$

(01) O financiamento das atividades culturais tem dois paradigmas clássicos: (02) o financiamento público e o mercantil. (03) O primeiro consiste na ação direta do estado (04) ou no financiamento com recursos estatais de práticas culturais da sociedade civil; (05) o segundo ancora-se na tradição liberal ou neoliberal, (06) cuja mais recente expressão são as correntes dominantes da economia criativa. (07) A partir de uma revisão teórica e da análise de duas políticas brasileiras - (08) o programa Cultura Viva e a Lei de Fomento ao Teatro da cidade de São Paulo - (09) argumentamos que essas experiências constituem a gênese de um terceiro paradigma que identificamos e desenvolvemos. (10) Esse paradigma não busca financiar produtos culturais, (11) mas o processo de produção cultural (12) e se orienta assim para a constituição de um direito social: (13) o direito de produzir cultura.

\footnotetext{
${ }^{2}$ No trecho, a numeração entre parênteses indica que o texto foi segmentado em atos. A RST e o MAM adotam unidades de análise diferentes. Como unidade de análise, a RST adota a noção de sentença, enquanto o MAM adota a noção de ato. Embora essas unidades não sejam equivalentes do ponto de vista conceitual, elas propiciam uma segmentação semelhante das produções textuais. Por isso e para que não seja necessário trabalhar com duas segmentações diferentes, adoto neste trabalho o ato como unidade mínima de análise.
} 


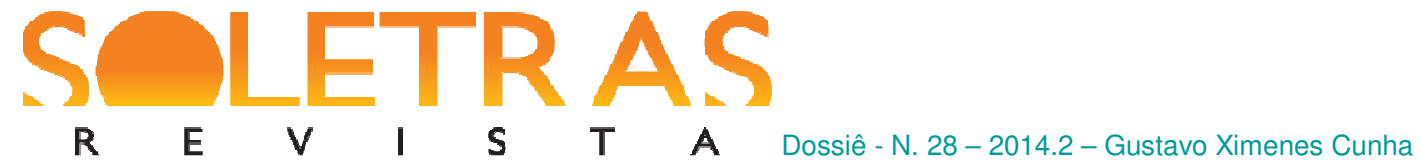

(14) Inicialmente discutimos de maneira esquemática os argumentos e críticas historicamente utilizados no debate pelo estabelecimento de políticas de financiamento público da cultura, sobretudo na modalidade editais públicos. (15) Em seguida apresentamos os argumentos e críticas relativos ao financiamento mercantil da cultura. (16) Mostramos que, (17) embora diferentes e antagônicas, (18) essas duas modalidades de financiamento têm em comum o tratamento mercantil dos bens e serviços culturais. (19) A partir deste pano de fundo conceitual, (20) discutimos duas experiências brasileiras recentes que, (21) ao deslocar o foco do financiamento do produto para o processo, (22) apontam para um tratamento não mercantil da cultura. (23) Tomamos esses elementos como ponto de partida, (24) os depuramos (25) e os desenvolvemos num modelo do qual tiramos todas as consequências: (26) pensar o financiamento cultural como o direito de produzir cultura (LIMA; ORTELLADO, 2013, p. 351-382).

O estudo será realizado em três momentos, correspondentes aos três itens deste trabalho. Primeiramente, apresento a RST para mostrar que ela possibilita um estudo bastante detalhado das relações retóricas, evidenciando as várias relações que o texto apresenta. Na sequência, apresento o MAM e mostro que ele permite generalizações importantes sobre a construção do texto já na primeira etapa da análise, a que estuda as categorias genéricas de relações do texto. Por fim, na terceira parte, procederei à aproximação das duas abordagens, a fim de defender que tanto a RST quanto o MAM são abordagens que oferecem ferramentas de análise adequadas para o estudo a macrossintaxe do discurso, mas que cada abordagem dá atenção para determinados aspectos da articulação textual que, se considerados por ambas as abordagens, permitiriam que cada uma realizasse um estudo mais eficaz da articulação textual.

\section{A Teoria da Estrutura Retórica do Texto}

A RST constitui uma abordagem que se preocupa em explicar a construção da coerência dos textos, a partir da descrição de como os seus constituintes se articulam. Nesse sentido, a coerência de um texto resulta da função que cada um dos seus constituintes desempenha em relação a outro constituinte (TABOADA, 2006). Assim, a RST é uma teoria descritiva, cujo objetivo consiste em caracterizar as relações retóricas (proposições relacionais) que emergem da combinação dos constituintes textuais (ANTONIO, 2004, 2008).

Para essa teoria, as relações retóricas se estabelecem em todos os níveis da estrutura textual, tanto no nível dos constituintes mínimos (as sentenças), como no nível dos 
$\begin{array}{lllllll}\text { R } & \text { E } & \text { V } & \text { I } & \text { S } & \text { T } & \text { A Dossiê- N. 28-2014.2-Gustavo Ximenes Cunha }\end{array}$

constituintes formados por porções maiores do texto. Por esse motivo, postula-se que "os textos são formados por grupos organizados de orações que se relacionam hierarquicamente entre si” (ANTONIO, 2004, p. 39). As sentenças de um texto e os grupos em que se organizam podem se combinar por meio de dois tipos de relações:

- Relações núcleo-satélite, em que um constituinte textual (o satélite) é subsidiário de outro (o núcleo).

- Relações multinucleares, em que um constituinte textual não é subsidiário do outro, cada um dos quais funcionando como núcleo distinto.

A hierarquia entre os constituintes de um texto se verifica à medida que são definidas as relações que se estabelecem entre as porções de um texto. E é dessas relações (núcleo-satélite ou multinucleares) que surgem as relações retóricas ou proposições relacionais. A definição das proposições relacionais não leva em conta critérios formais, advindos da sintaxe, mas sim critérios funcionais e pragmáticos. Assim, critérios como as intenções (presumidas ou declaradas) do enunciador e os efeitos do texto sobre o universo de crenças do enunciatário participam da definição dessas proposições.

Dessa forma, é possível perceber que a estrutura por meio da qual a RST propõe representar a organização dos constituintes do texto não deve ser encarada como resultante de uma combinatória formal. Ainda que o fenômeno das proposições relacionais seja “combinacional” (MANN; THOMPSON, 1986), a estrutura retórica é um instrumento de análise com o qual o estudioso da língua pode explicitar a sua interpretação de como o autor organizou o texto e qual função cada constituinte textual exerce.

$\mathrm{Na}$ continuação deste item, exponho a análise da introdução do artigo científico, apresentada no começo deste trabalho, do ponto de vista da RST. A figura 1 apresenta a macroestrutura retórica dessa introdução.

Figura 1

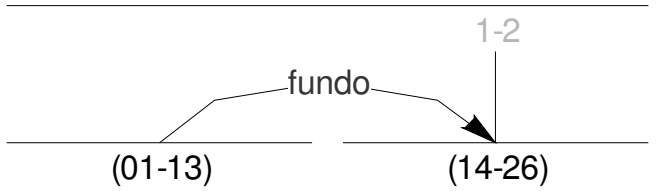




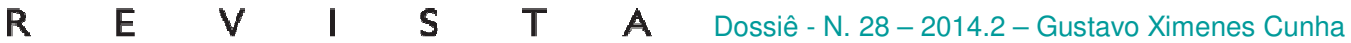

No nível global da organização do texto, o primeiro parágrafo (satélite) exerce um papel de fundo em relação ao segundo parágrafo (núcleo). Isso porque os autores, ao tratarem no satélite dos paradigmas clássicos de financiamento das atividades culturais, trazem informações que auxiliam o leitor a compreender o núcleo, onde informam a organização e o objetivo do artigo.

A seguir, apresento a estrutura retórica de cada parágrafo da introdução do artigo. A figura 2 representa a estrutura retórica do primeiro parágrafo.

Figura 2

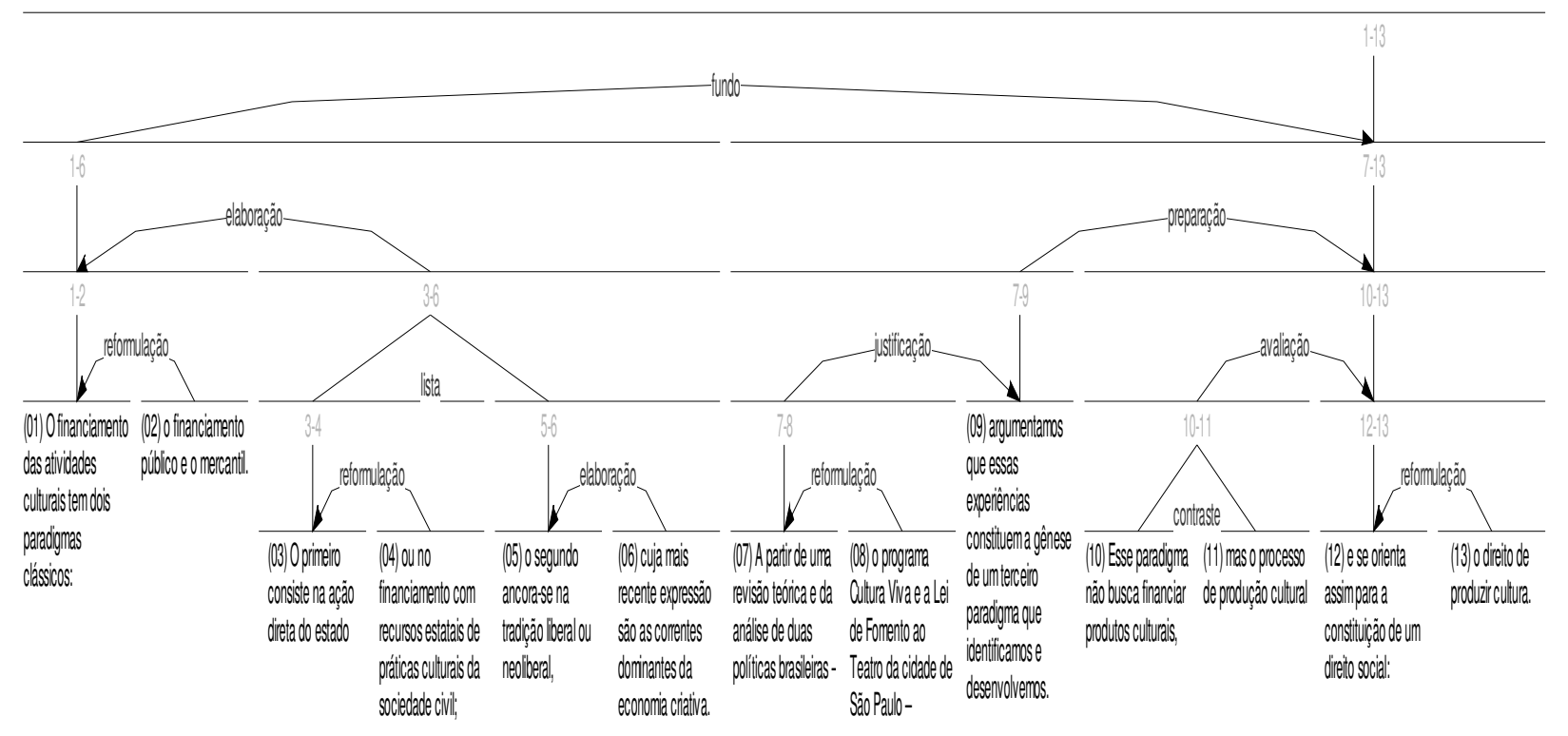

Nesse parágrafo, os autores mencionam os paradigmas clássicos do financiamento das atividades culturais para defenderem a proposição de um terceiro. Por isso, a porção formada pelas unidades (01-06), onde eles apresentam os paradigmas clássicos, funciona como um fundo para o leitor compreender a porção formada pelas unidades (07-13), onde eles informam que o artigo vai apresentar um terceiro paradigma.

$\mathrm{Na}$ porção (01-06), os autores informam, em (01-02), que o financiamento das atividades culturais tem dois paradigmas clássicos e, em (03-06), dão uma descrição sucinta de cada um desses paradigmas. Assim, as unidades (03-06) trazem informações que elaboram as informações dadas em (01-02). Em (03-06), os segmentos que apresentam os dois paradigmas se articulam por uma relação multinuclear de lista.

Em (07-09), os autores informam que sua intenção com o artigo é argumentar a favor de um terceiro paradigma. Com essa informação, eles preparam o leitor para as informações 


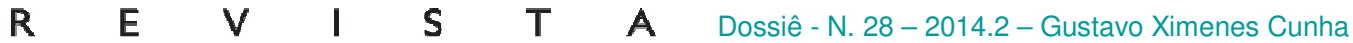

contidas na porção textual (10-13), onde vão caracterizar de forma breve esse paradigma. Em (10-13), os autores fazem uma avaliação sobre o terceiro paradigma no satélite, formado por (10-11), avaliação que vai ajudá-los a evidenciar, no núcleo, formado por (12-13), sua atitude positiva em relação a esse paradigma.

Feita a análise da estrutura retórica do primeiro parágrafo, passo à análise da estrutura do segundo, a qual pode ser vista na figura 3.

\section{Figura 3}

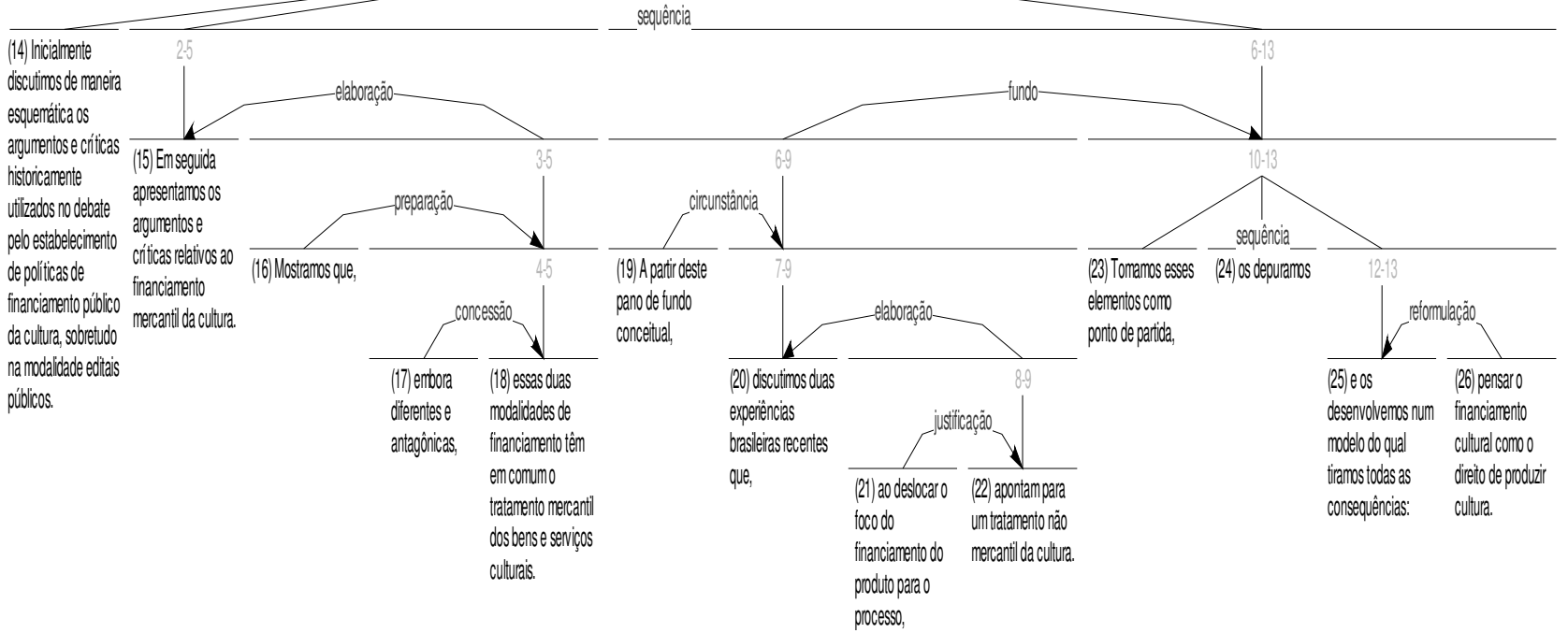

No nível macroestrutural, os autores organizam as informações desse parágrafo por uma relação de sequência. Como é comum acontecer no parágrafo final das introduções de artigos científicos, os autores apresentam as seções do trabalho em ordem cronológica. Assim, a unidade (14) apresenta a primeira seção, a porção formada pelas unidades (15-18) apresenta a segunda, e a porção formada por (19-26) apresenta as demais seções.

Em (15-18), as informações do núcleo (15) são elaboradas pelas informações do satélite (16-18). Isso porque os autores dizem, em (15), que na seção a que se referem vão criticar o financiamento mercantil da cultura. E, em (16-18), eles já antecipam parte dessas críticas, dizendo: "essas duas modalidades de financiamento têm em comum o tratamento mercantil dos bens e serviços culturais".

Em (19-26), a porção formada pelas unidades (19-22) constitui um satélite que funciona como fundo para as informações trazidas no núcleo, formado por (23-26). No satélite, os autores informam que a parte final do artigo vai apresentar dois estudos que "apontam para 


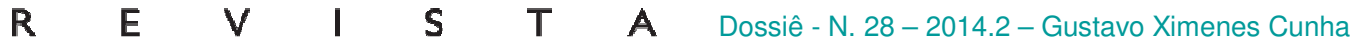

um tratamento não mercantil da cultura". No núcleo, os autores informam que esses estudos vão funcionar como a base para a proposição do terceiro paradigma para o financiamento das atividades culturais. Assim, para entender o núcleo, é preciso ler o satélite que o antecede.

No próximo item, mostro como a introdução do artigo científico pode ser analisada do ponto de vista do Modelo de Análise Modular.

\section{O Modelo de Análise Modular do Discurso}

No MAM, o estudo das relações de discurso se faz no interior da forma de organização relacional $^{3}$. Nessa forma de organização, as informações do módulo hierárquico são combinadas com informações dos módulos lexical, sintático e referencial.

No módulo hierárquico, considera-se que "toda intervenção linguageira (cumprimento, pedido, asserção etc.) constitui uma PROPOSIÇÃO, que desencadeia um processo de negociação entre os interactantes" (ROULET; FILLIETTAZ; GROBET, 2001, p. 57). Assim, um diálogo formado por uma pergunta (Que horas são?), por uma resposta (São nove horas.) e por um agradecimento (Obrigado.) evidencia um processo em que uma proposição (a pergunta) desencadeia uma reação (a resposta), que motiva uma ratificação (o agradecimento).

Nas interações efetivamente realizadas, as fases desse processo de negociação (proposição, reação, ratificação) assumem configurações complexas, raramente se reduzindo à intervenção de um único ato. Assim, a toda unidade textual subjaz um processo de negociação complexo, e é esse processo que as estruturas geradas no módulo hierárquico buscam reconstruir e tornar visíveis.

As estruturas hierárquicas são formadas pelos três tipos de constituintes que os interactantes produzem em toda interação verbal: trocas, intervenções e atos.

- Troca: unidade textual máxima, que é formada por intervenções que refletem as várias proposições, reações e ratificações de uma negociação.

\footnotetext{
${ }^{3}$ O MAM é uma abordagem para o estudo da complexidade do discurso como um todo e não apenas para o estudo da articulação textual. Assim, em linhas bastante gerais, para esse modelo, o discurso resulta da interrelação de informações provenientes de três dimensões: linguística, textual e situacional. Cada dimensão compreende módulos responsáveis pela descrição de subdomínios do discurso. Assim, a dimensão situacional abarca os módulos referencial e interacional, a dimensão textual, o módulo hierárquico, e a dimensão linguística, os módulos sintático e lexical. Para uma compreensão aprofundada do modelo, ver Roulet, Filliettaz e Grobet (2001), Marinho (2004), Cunha (2013, 2014).
} 


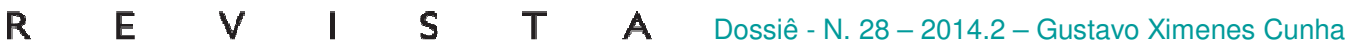

- Intervenção: unidade constitutiva da troca, que pode ser formada por apenas um ato, mas que costuma apresentar uma configuração complexa, da qual participam outras intervenções, atos e até mesmo trocas.

- Ato: unidade textual mínima, que constitui a menor unidade delimitada por uma e outra passagem da memória discursiva.

Combinando essas informações hierárquicas com informações lexicais, referenciais e sintáticas, o estudo da forma de organização relacional se faz em duas etapas. Na primeira, identificam-se as relações ilocucionárias e interativas genéricas entre os constituintes da estrutura hierárquica e informações da memória discursiva. Na segunda etapa, determina-se a relação específica entre um constituinte em particular e uma informação da memória discursiva.

Na primeira etapa, a identificação das relações ilocucionárias e interativas genéricas se baseia em uma lista reduzida de categorias de relações, as quais são consideradas suficientes para descrever todas as formas de discurso, tanto dialogal como monologal. A noção de argumento, por exemplo, é utilizada como categoria genérica para recobrir as relações interativas específicas de causa, explicação, justificação, argumento potencial, etc.

$\mathrm{Na}$ forma de organização relacional, as relações ilocucionárias caracterizam as intervenções que constituem as trocas. Essas relações podem ser iniciativas ou reativas, dependendo do lugar em que ocorre a intervenção na estrutura hierárquica. Distinguem-se três categorias genéricas de relações ilocucionárias iniciativas (interrogação, pedido e informação) e duas categorias genéricas de relações ilocucionárias reativas (resposta e ratificação) (ROULET; FILLIETTAZ; GROBET, 2001).

As relações interativas, por sua vez, caracterizam os constituintes das intervenções. Distinguem-se oito categorias genéricas de relações interativas: argumento, contra-argumento, reformulação, topicalização, tempo, preparação, comentário e clarificação (ROULET; FILLIETTAZ; GROBET, 2001, CUNHA, 2012).

Como foi dito, o estudo das relações de discurso genéricas constitui a primeira etapa da análise da forma de organização relacional. Aprofundando esse estudo, a segunda etapa descreve as relações ilocucionárias e interativas específicas entre um constituinte textual e uma informação da memória discursiva. Essa descrição é importante, porque permite distinguir, por exemplo, as relações de argumento marcadas por conectores daquelas que não 


\section{$\begin{array}{llllllll}\mathbf{R} & \mathbf{E} & \mathbf{V} & \mathbf{I} & \mathbf{S} & \mathbf{T} & \mathbf{A} & \text { Dossiê- N. 28-2014.2-Gustavo Ximenes Cunha }\end{array}$}

apresentam nenhuma marcação linguística ou uma relação de argumento marcada por porque de relações que são marcadas por pois, portanto, aliás, etc (ROULET; FILLIETTAZ; GROBET, 2001).

$\mathrm{Na}$ análise relacional, o estudo das especificidades de cada relação discursiva é feito com a aplicação de um cálculo inferencial, que se baseia nas propriedades linguísticas, hierárquicas e referenciais dos constituintes do texto. Para realizar esse cálculo, formulam-se premissas com base nas informações linguísticas dos constituintes textuais. Nessas premissas, as informações linguísticas são enriquecidas pelos referentes que saturam pronomes, expressões nominais e desinências verbais, como as instâncias agentivas que participam da interação e demais elementos dêiticos. Caso a relação seja marcada por conector, formula-se, em seguida, outra premissa a partir da instrução (gramatical ou pragmática) desse conector. Finalmente, com base nessas premissas, chega-se à conclusão ou interpretação final sobre a relação específica considerada (ROULET, 2003).

$\mathrm{Na}$ sequência, apresento o resultado da análise da primeira etapa da forma de organização relacional. Tratando da introdução do artigo, analiso, inicialmente, a macroestrutura do texto e, em seguida, as porções que a constituem. A figura 4 representa a macroestrutura ${ }^{4}$.

\section{Figura 4}

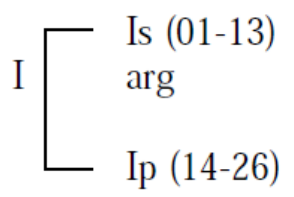

No nível macroestrutural, os autores iniciam o texto com uma grande intervenção, correspondente ao primeiro parágrafo, em que apresentam os dois paradigmas clássicos para o financiamento de atividades culturais e informam que a finalidade do artigo é defender a existência de um terceiro paradigma. Essa primeira intervenção funciona como argumento para a intervenção seguinte, em que, diante das informações expostas na primeira, os autores explicitam as ações que serão realizadas em cada seção do texto para alcançar a finalidade proposta.

\footnotetext{
${ }^{4}$ Intervenção $=$ I. Subordinada $=$ S. Principal $=$ P. Argumento $=$ arg. 

R
S T
A Dossiê - N. 28-2014.2-Gustavo Ximenes Cunha

A seguir, apresento a análise da forma de organização relacional de cada intervenção da macroestrutura apresentada. A figura 5 apresenta a organização da intervenção formada pelos atos $(01-13)^{5}$.

\section{Figura 5}

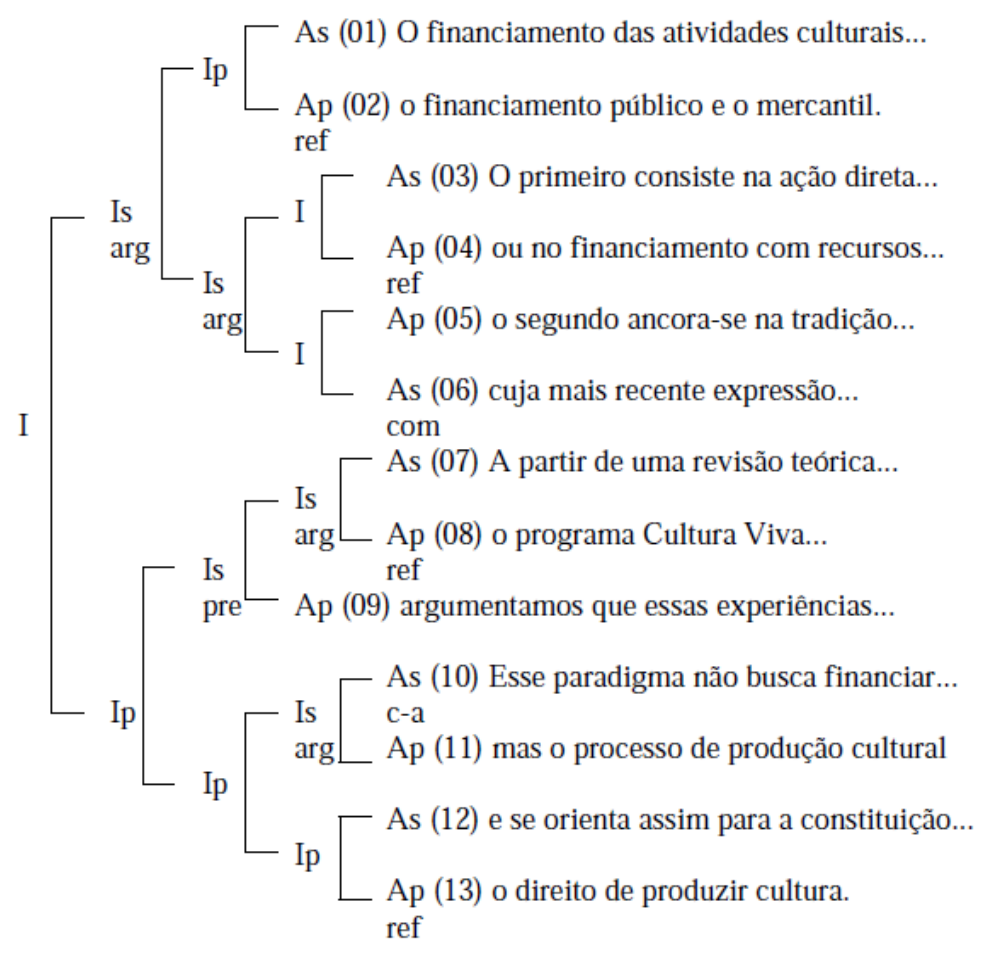

Nessa intervenção, a apresentação dos paradigmas para o financiamento de atividades culturais (atos 01-06) funciona como argumento para os autores justificarem a necessidade de um terceiro paradigma (atos 07-13). Por isso, os atos (07-13) formam uma intervenção que subordina a intervenção formada pelos atos (01-06). Afinal, a proposição da terceira abordagem é a finalidade principal do trabalho.

Na Is (01-06), os atos (03-06) desenvolvem a informação dada nos dois primeiros atos. Assim, os atos (03-06) são subordinados à Ip (01-02) e funcionam como argumento para a informação contida na intervenção.

$\mathrm{Na}$ Ip (07-13), os atos (07-09), porque apenas informam que os autores defendem um terceiro paradigma para o financiamento de cultura, constituem uma preparação para a intervenção principal formada pelos atos (10-13). Isso porque é nessa intervenção que os autores informam o teor do terceiro paradigma que propõem.

\footnotetext{
${ }^{5}$ Ato $=$ A. Reformulação $=$ ref. Comentário $=$ Com. Preparação $=$ pre. Contra-argumento $=$ c-a. Tempo $=$ tem.. 


\section{$\begin{array}{llllllll}\text { R } & \text { E } & \text { V } & \text { I } & \text { S } & \text { T } & \text { A } & \text { Dossiê- N. 28-2014.2-Gustavo Ximenes Cunha }\end{array}$}

$\mathrm{Na}$ Is (07-09), os atos (07-08), trazendo a base teórica do estudo, funcionam como argumento para a os autores defenderem, no Ap (09), a proposição do terceiro paradigma. $\mathrm{Na}$ Ip (10-13), os autores informam em (12-13) a finalidade principal do paradigma que propõem: orientar para a constituição de um direito social: o direito de produzir cultura. Porque os atos (12-13) explicitam a finalidade principal desse paradigma, eles subordinam retroativamente os atos (10-11), que apenas expõem que esse novo paradigma busca financiar não produtos culturais, mas o processo de produção cultural.

A figura 6 apresenta a organização da intervenção formada pelos atos (14-26).

\section{Figura 6}

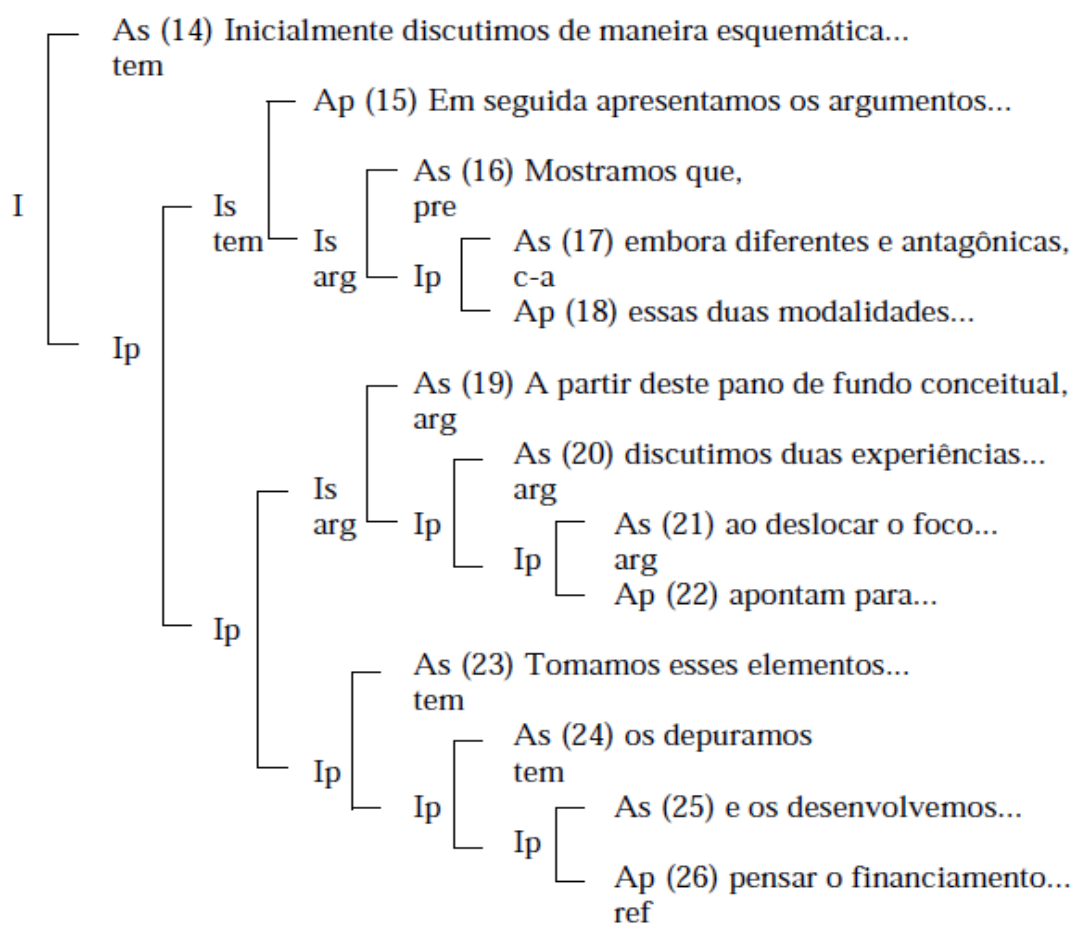

$\mathrm{Na}$ Ip (14-26), os autores apresentam a organização do texto, explicitando como as informações se distribuem ao longo das seções. Como apontado no item anterior, o parágrafo final das introduções de artigos científicos costuma apresentar as informações na ordem em que estas aparecerão no texto. Assim, nessa intervenção, há várias relações de tempo, já que essas informações se sucedem cronologicamente. Por apresentar as informações da primeira seção do artigo, o ato (14) é subordinado à Ip (15-26). Nessa intervenção, os atos (15-18), porque apresentam as informações contidas na segunda seção do trabalho, se subordinam à intervenção seguinte, formada pelos atos (19-26). Nessa intervenção, a Is (19-22) e a Ip (23- 
$\begin{array}{llllllll}\mathbf{R} & \mathbf{E} & \boldsymbol{V} & \mathbf{I} & \mathbf{S} & \mathbf{T} & \mathbf{A} & \text { Dossiê- N. 28-2014.2-Gustavo Ximenes Cunha }\end{array}$

26) não se articulam por uma relação de tempo, embora essas intervenções apresentem as duas últimas seções. A Is (19-22) funciona como argumento para a Ip (23-26), porque a intervenção subordinada informa que a seção de que trata vai motivar o paradigma a ser apresentado na última seção, da qual trata a intervenção principal.

No interior das intervenções que apresentam cada seção do trabalho, há um predomínio de relações argumentativas, o que se explica pela própria finalidade do artigo, a saber, defender um paradigma novo para o financiamento público da cultura.

Como exposto no início, o estudo da forma de organização relacional se faz em duas etapas. Feito o estudo das relações genéricas, procede-se à identificação das relações específicas, por meio do cálculo dessa relação. Por motivo de espaço, realizo o cálculo de uma relação de discurso apenas, a que se dá entre os dois primeiros atos do texto, reproduzidos a seguir: (01) O financiamento das atividades culturais tem dois paradigmas clássicos: (02) o financiamento público e o mercantil.

O quadro abaixo traz o percurso que permite chegar à identificação da relação específica.

\begin{tabular}{|l|l|l|}
\hline Premissa 1 & $\begin{array}{l}\text { Informação linguística } \\
\text { enriquecida }\end{array}$ & $\begin{array}{l}\text { Os autores (A) dizem aos leitores (L) que o financiamento } \\
\text { das atividades culturais tem dois paradigmas clássicos. }\end{array}$ \\
\hline Premissa 2 & $\begin{array}{l}\text { Informação linguística } \\
\text { enriquecida }\end{array}$ & $\begin{array}{l}\text { A dizem a L que os dois paradigmas clássicos de } \\
\text { financiamento das atividades culturais são o financiamento } \\
\text { público e o mercantil. }\end{array}$ \\
\hline Premissa 3 & $\begin{array}{l}\text { Informação gráfica } \\
\text { (instrução dada pelos } \\
\text { dois-pontos) }\end{array}$ & $\begin{array}{l}\text { Uma das instruções dadas por esse sinal de pontuação é a de } \\
\text { que as informações por ele conectadas são equivalentes do } \\
\text { ponto de vista semântico (DAHLET, 2006). }\end{array}$ \\
\hline Conclusão & Interpretação & $\begin{array}{l}\text { Primeiro, A dizem a L que o financiamento das atividades } \\
\text { culturais tem dois paradigmas clássicos. Depois, eles } \\
\text { reformulam essa informação, esclarecendo que esses dois } \\
\text { paradigmas são o financiamento público e o mercantil. }\end{array}$ \\
\hline
\end{tabular}

Quadro 1 - Cálculo da relação específica

Com esse percurso inferencial, é possível chegar à interpretação de que entre os atos (01) e (02) os autores estabelecem uma relação específica de reformulação parafrástica ${ }^{6}$, já que entre as informações expressas em cada ato há uma relação de equivalência semântica. Afinal, os dois paradigmas clássicos (ato 01) são o financiamento público e o mercantil (ato 02).

\footnotetext{
${ }^{6}$ Conforme Rossari (1993, 2000), a categoria genérica de reformulação se subdivide em duas subcategorias de relações: a parafrástica e a não-parafrástica. A parafrástica se caracteriza pela existência de uma equivalência semântica entre dois constituintes textuais (atos ou intervenções). Já a não-parafrástica permite ao locutor operar uma retrointerpretação da informação expressa no primeiro constituinte textual.
} 


\section{$\begin{array}{llllllll}\mathbf{R} & \mathbf{E} & \mathbf{V} & \mathbf{I} & \mathbf{S} & \mathbf{T} & \text { A } & \text { Dossiê- N. 28-2014.2-Gustavo Ximenes Cunha }\end{array}$}

Após estudar a introdução do artigo científico com base nos instrumentos de análise das duas abordagens - a RST e o MAM -, no próximo item, estabeleço possíveis aproximações entre essas abordagens.

\section{Aproximando a RST e o MAM: em busca de semelhanças e diferenças}

A partir das análises empreendidas nos itens anteriores, neste item evidencio, inicialmente, as semelhanças que, do meu ponto de vista, há entre as duas abordagens apresentadas. Em seguida, aponto em que medida as abordagens podem se beneficiar da consideração das diferenças que particularizam cada uma delas.

No que se refere à estruturação do texto, a RST e o MAM partilham o pressuposto de que as relações retóricas ou de discurso não constituem problemáticas simples, já que não dizem respeito a um fenômeno apenas linguístico. Em ambas as abordagens, a emergência de uma relação é motivada mais por fatores pragmáticos ou situacionais do que por fatores estritamente lexicais ou sintáticos. Por esse motivo, a RST e o MAM permitem ao analista obter uma representação muito semelhante da articulação dos constituintes de uma produção textual.

Assim, as duas abordagens permitiram mostrar que a introdução do artigo analisado se constitui de duas grandes porções textuais, sendo a primeira subsidiária ou subordinada em relação à segunda. Da mesma forma, no interior dessas duas porções textuais, os instrumentos de análise propostos pelos dois modelos permitiram uma compreensão próxima de quais informações são centrais e de quais informações são periféricas.

Em suma, a RST e o MAM são modelos que permitem um estudo explícito e rigoroso da macrossintaxe do discurso, porque ambos, como apontado por Rossari (2001, p. 62, tradução minha) em estudo que também propõe aproximar as duas abordagens, compartilham estes objetivos:

(i) permitir identificar as estruturas hierárquicas do texto;

(ii) permitir descrever relações funcionais entre partes do texto;

(iii) permitir segmentar o texto em unidades mínimas e identificar o tamanho dos segmentos concernidos pelas relações.

Fornecendo ferramentas de análise com que estudar a macrossintaxe do discurso, essas abordagens se filiam, assim, à corrente mais ampla dos estudos pragmáticos, porque, de modo geral, investigam as manobras discursivas que o usuário da língua realiza ao construir o 


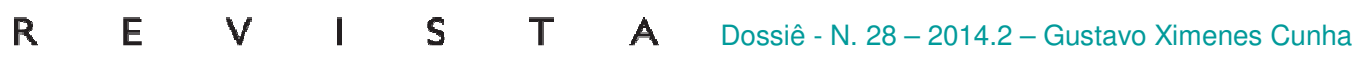

discurso, na tentativa de alcançar determinado fim junto ao interlocutor. E, como já ressaltado em Cunha (2012), permitem ultrapassar, ao mesmo tempo, o reducionismo da abordagem gramatical tradicional e o impressionismo de algumas abordagens do discurso, que se limitam a uma interpretação do conteúdo.

Entretanto, como apontado por Rossari (2001), a RST e o MAM apresentam diferenças, que precisam ser levadas em conta. Porém, neste trabalho, adoto uma perspectiva totalmente divergente em relação à adotada por Rossari. Para ela, as semelhanças entre os modelos seriam apenas de superfície, já que, segundo a autora, a RST seria um modelo que se baseia nos processos cognitivos e interacionais em jogo na construção do texto, enquanto o MAM seria um modelo essencialmente formalista e, portanto, ancorado nas marcas linguísticas e na posição dos constituintes textuais.

Defendo que essa caracterização da forma como o modelo modular estuda a articulação textual é equivocada e redutora, tendo em vista o fato de que as estruturas hierárquicorelacionais são resultantes, como visto no item anterior, de um processo de negociação instaurado entre os interlocutores. Ou seja, o estudo da articulação textual no modelo é totalmente ancorado na interação de que a materialidade textual é o produto. Porém, o trabalho de Rossari não faz qualquer menção ao processo de negociação que subjaz às estruturas hierárquicas, processo que é detalhadamente exposto em Roulet, Filliettaz e Grobet (2001, cap. 3).

Porque, então, ambas as abordagens concebem a articulação textual como um fenômeno profundamente interacional e dependente dos objetivos comunicativos do produtor do texto, considero que elas são mais convergentes do que divergentes, embora tenham se constituído em contextos diversos. Para apontar essa convergência, na sequência deste item, não busco uma síntese das duas abordagens, o que significaria propor uma terceira abordagem. Longe disso, meu propósito é apenas o de mostrar em que medida as propostas ou os postulados de uma abordagem poderiam auxiliar a outra a compreender a articulação textual de maneira mais eficaz.

Discuto três aspectos das duas abordagens que me parecem ser os que, a princípio, mais as distinguem. Esses aspectos são relativos (i) às listas de relações de uma e de outra abordagem, (ii) ao estudo de textos dialogais e (iii) às relações entre constituintes de mesmo estatuto hierárquico. 


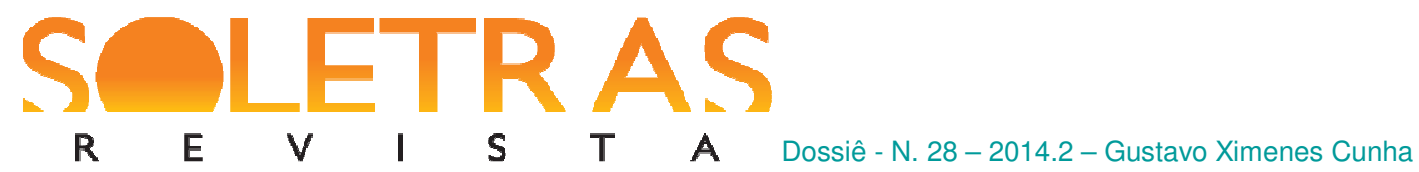

\subsection{As listas de relações retóricas/de discurso}

Diferentemente do MAM, a RST estuda a articulação textual com base em uma lista de aproximadamente vinte e cinco relações retóricas, lista que pode variar de um autor para outro. Já o MAM se baseia em uma lista reduzida de categorias genéricas para estudar as relações de discurso. Nesse modelo, são propostas oito categorias de relações interativas, que são as que ocorrem no interior das intervenções (argumento, contra-argumento, reformulação, topicalização, tempo, preparação, comentário e clarificação), e cinco categorias de relações ilocucionárias, que são as que ligam os constituintes da troca (interrogação, pedido, informação, resposta e ratificação). E, caso o analista queira detalhar as relações genéricas, ele parte para a segunda etapa do estudo da forma de organização relacional, em que é calculada a relação específica entre as informações do texto.

Trabalhar com uma lista detalhada de relações, como o faz a RST, tem a vantagem de permitir ao analista obter uma caracterização precisa da maneira como o locutor articulou as informações do texto. Uma caracterização como essa só é possível, no MAM, quando o analista procede ao cálculo da relação específica, o que, porém, raramente costuma ser feito para todo o texto, tendo em vista o detalhamento dos quadros que representam esse cálculo.

Mas, se uma lista extensa de relações tem essa vantagem, ela traz como inconveniente não permitir ao analista obter generalizações importantes sobre a estratégia de construção do texto. Assim, a análise sob o ponto de vista da RST não permite perceber que a introdução do artigo estudado possui um perfil relacional argumentativo, tendo em vista a predominância de relações genéricas de argumento. Uma percepção desse tipo só de obtém, se o analista trabalha com categorias genéricas de relações, como o faz o MAM.

Mas, na RST, muitas relações retóricas são motivadas, por exemplo, pela busca do produtor do texto de convencer o leitor ou ouvinte a realizar determinada ação ou a pensar de outra forma. Nesse sentido, muitas relações são argumentativas. No MAM, a categoria genérica de argumentação tem como fim abarcar todas as relações específicas em que o produtor do texto quer exatamente convencer o outro. Assim, a aproximação das duas abordagens pode ser interessante para se perceber que as categorias de relações genéricas, propostas no MAM, poderiam abarcar conjuntos de relações retóricas, propostas pela RST. Desenvolvendo o exemplo dado, a categoria genérica de argumentação abrigaria as relações retóricas de elaboração, evidência, justificação, motivação, etc. Com essa aproximação, é 
$\begin{array}{llllllll}\text { R } & \text { E } & \text { V } & \text { I } & \text { S } & \text { T } & \text { A Dossiê- N. 28-2014.2-Gustavo Ximenes Cunha }\end{array}$

possível obter uma caracterização detalhada da articulação textual e, ao mesmo tempo, perceber o perfil relacional de um texto.

\subsection{O estudo de textos dialogais}

De modo geral, as análises propostas com base na RST focalizam textos escritos e monologais. Embora haja propostas para a aplicação dessa abordagem no estudo de textos dialogais (TABOADA, 2006), a RST foi desenvolvida essencialmente para estudar textos monologais. Já o MAM, desde suas primeiras versões (ROULET et al, 1985), procurou dar conta da articulação textual de textos tanto dialogais quanto monologais, tendo em vista que uma das bases do modelo é o princípio bakhtiniano de que toda produção textual, oral ou escrita, é essencialmente dialógica. Por isso, a base do estudo da articulação textual, nessa abordagem, é a noção de processo de negociação, a qual se materializa na maior unidade dialogal, a troca.

A percepção de que a maior unidade dialogal é a troca fez com que o estudo da articulação textual no MAM considerasse as relações de discurso (iniciativas e/ou reativas) que se dão entre as intervenções constitutivas da troca. Assim, vimos que o artigo em estudo é uma das intervenções de uma troca. Nessa troca, esse artigo constitui uma reação em relação aos dois paradigmas clássicos de financiamento das atividades culturais e às duas políticas de financiamento cultural, os quais são mencionados no texto. A percepção desse processo de negociação entre diferentes teóricos (os autores do artigo e os proponentes dos paradigmas clássicos) é fundamental para a compreensão das características do artigo. Afinal, o perfil relacional argumentativo dessa introdução parece se explicar, em grande medida, pela função de reação que o artigo exerce na troca de que faz parte.

Uma noção como a de processo de negociação instaura no estudo da articulação textual uma dimensão dialógica mais ampla, contribuindo para uma compreensão mais adequada de como se dá a articulação textual em toda produção discursiva, além de mostrar que não há uma dicotomia entre texto monologal e texto dialogal, já que mesmo os textos monologais, como o artigo estudado, constituem uma das fases de um processo de negociação mais amplo.

Sendo assim, para que a RST possa dar conta, de maneira consistente, das relações retóricas que se dão, por exemplo, entre os turnos de uma conversa ou de um bate papo on line, seria interessante que nessa abordagem fosse contemplada uma noção como a de 


\section{$\begin{array}{llllllll}\mathbf{R} & \mathbf{E} & \mathbf{V} & \mathbf{I} & \mathbf{S} & \mathbf{T} & \mathbf{A} & \text { Dossiê- N. 28-2014.2-Gustavo Ximenes Cunha }\end{array}$}

processo de negociação. Uma noção como essa permitiria que os textos monologais e escritos (textos publicitários, receitas culinárias, artigos científicos, reportagens, etc) fossem entendidos como parte de trocas mais amplas e que as relações retóricas inicialmente identificadas em corpora de textos monologais não fossem simplesmente transpostas para o estudo de textos dialogais. Na RST, o desenvolvimento de uma noção como a de processo de negociação poderia resultar na proposição de uma lista das relações retóricas que se dão entre os turnos de fala.

\subsection{As relações multinucleares}

$\mathrm{Na} \mathrm{RST}$, as relações multinucleares dão conta do fato de que pode haver relações retóricas entre dois constituintes textuais com o mesmo estatuto hierárquico (núcleos). Assim, no artigo analisado, entre as porções (03-04) e (05-06), há uma relação de lista, porque os autores apresentam em cada porção textual um paradigma diferente de financiamento cultural.

Já no MAM, não se prevê a possibilidade de haver relações de discurso entre constituintes textuais com o mesmo estatuto hierárquico. Assim, as relações de discurso só existem, quando um constituinte é principal e o outro, subordinado. Por isso, na análise da forma de organização relacional do artigo, as intervenções (03-04) e (05-06) são apresentadas como sendo coordenadas, já que uma não é principal em relação à outra, e entre elas, para o MAM, não há nenhuma relação de discurso. Esse postulado do modelo é problemático, porque encobre as relações de discurso que podem existir entre dois constituintes do texto e, consequentemente, fornece uma representação incompleta das escolhas que o produtor de um texto faz para se comunicar.

Dessa forma, para que o MAM possa fornecer uma descrição mais completa e adequada da articulação textual, seria proveitoso considerar que mesmo entre constituintes de igual estatuto hierárquico o produtor do texto pode estabelecer relações de discurso, como as de lista, conjunção, disjunção, etc.

\section{Considerações finais}

Neste trabalho, aproximei dois modelos teóricos do texto/discurso: a Teoria da Estrutura Retórica (Rhetorical Structure Theory - RST) e o Modelo de Análise Modular (Modèle 
$\begin{array}{lllllll}\text { R } & \text { E } & \text { V } & \text { I } & \text { S } & \text { T } & \text { A Dossiê- N. 28-2014.2-Gustavo Ximenes Cunha }\end{array}$

d'Analyse Modulaire - MAM). Essa aproximação teve como finalidade verificar em que medida são complementares as ferramentas de análise propostas em cada modelo para o estudo da articulação textual.

Como estratégia para proceder a esse estudo, analisei a mesma produção textual (a introdução de um artigo científico) do ponto de vista de cada uma das abordagens. A partir desses estudos, foi possível comparar as abordagens, verificando semelhanças e diferenças entre elas. No que se refere às semelhanças, tanto a RST quanto o MAM oferecem ferramentas de análise adequadas para o estudo a macrossintaxe do discurso. Além disso, ambas se filiam à corrente mais ampla dos estudos pragmáticos, porque investigam as manobras discursivas que o produtor do texto realiza, a fim de provocar determinados efeitos de sentido junto ao interlocutor.

Quanto às diferenças, defendi que cada abordagem dá atenção a determinados aspectos da articulação textual que, se forem levados em conta por ambas as abordagens, permitiriam que cada uma realizasse um estudo mais eficaz da articulação textual. Assim, propus, inicialmente, uma complementação entre as listas de relações retóricas da RST e as categorias de relações de discurso genérica do MAM. Em seguida, sugeri que uma noção dialógica como a de processo de negociação do MAM fosse desenvolvida pela RST, a fim de que essa abordagem possa dar conta das relações entre os turnos de fala. Por fim, propus que no MAM seja revisto o postulado de que entre constituintes de mesmo estatuto hierárquico não há relações de discurso, uma vez que, como mostra a RST, há a possibilidade de haver relações multinucleares.

Como exposto no item anterior, este trabalho não teve a intenção de propor uma síntese entre a RST e o MAM, síntese de que poderia resultar uma terceira abordagem para o estudo da articulação textual. Meu objetivo foi, antes, o de estabelecer pontos de convergência entre dois modelos para a realização desse estudo. Assim, ao invés de fomentar embates pouco produtivos entre modelos teóricos, esta proposta procurou construir uma ponte entre duas teorias, estabelecendo um diálogo produtivo.

\section{Referências bibliográficas:}

ANTONIO, J. D. Estrutura retórica e articulação de orações em narrativas orais e em narrativas escritas do português. 2004. 245f. Tese (Doutorado em Linguística) - Faculdade de Ciências e Letras, Universidade Estadual Paulista, Araraquara, 2004. 

R E
S T
A Dossiê- N. 28-2014.2-Gustavo Ximenes Cunha

ANTONIO, J. D. Estrutura retórica e combinação de orações em narrativas orais e em narrativas escritas do português brasileiro. Estudos Lingüísticos, v. 37, n. 1, p. 223-232, 2008.

CUNHA, G. X. A articulação discursiva do gênero artigo de opinião à luz de um modelo modular de análise do discurso. Filologia e Linguística Portuguesa, v. 14, 2012, p. 73-97.

CUNHA, G. X. A construção da narrativa em reportagens. 2013. 601f. Tese (Doutorado em Linguística) - Faculdade de Letras, Universidade Federal de Minas Gerais, Belo Horizonte.

CUNHA, G. X. Para entender o funcionamento do discurso: uma abordagem modular da complexidade discursiva. Curitiba: Appris, 2014.

DAHLET, V. As (man) obras da pontuação: usos e significações. São Paulo: Associação Editorial Humanitas; Fapesp, 2006.

MANN, W. C.; THOMPSON, S. A. Relational propositions in discourse. Discourse Processes, v. 9, n. 1, 1986, p. 57-90.

MARINHO, J. H. C. Uma abordagem modular e interacionista da organização do discurso. Revista da Anpoll, v. 16, 2004, p. 75-100.

ROSSARI, C. Les opérations de reformulation: analyse du processus et des marques dans une perspective contrastive français-italien. Berne: Lang, 1993.

ROSSARI, C. Connecteurs et relations de discours: des liens entre cognition et signification. Nancy: Presses universitaires de Nancy, 2000.

ROSSARI, C. Les relations de discours: approches rhétoriques, approches pragmatiques et approches sémantiques. Verbum, n. 1. 2001, p. 59-72.

ROULET, E. Une approche modulaire de la problematique des relations de discours. In: MARI, H. et al. Análise do discurso em perspectivas. Belo Horizonte: FALE/UFMG, 2003, p. 149-178.

ROULET, E. et al. L'Articulation du discours en français contemporain. Berne: Lang, 1985.

ROULET, E.; FILLIETTAZ, L.; GROBET, A. Un modèle et un instrument d'analyse de l'organisation du discours. Berne: Lang, 2001.

TABOADA, M. Discourse markers as signal (or not) of rhetorical relations. Journal of Pragmatics, v. 38, n. 4, p. 567-592, 2006. 


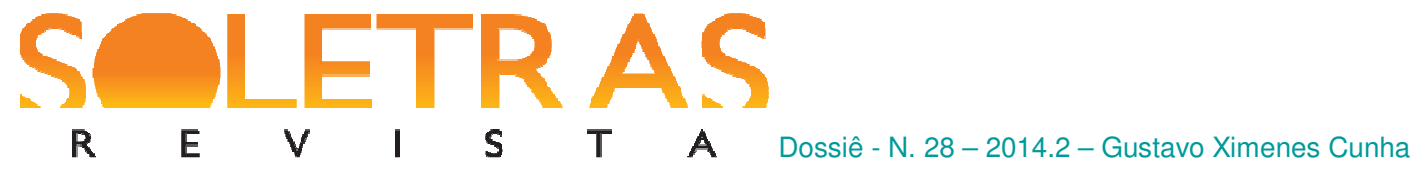

A study on textual articulation in different theoretical perspectives

\begin{abstract}
In this paper, I propose an approximation of two theoretical models of text: Rhetorical Structure Theory and the Modular Approach of Discourse Analysis. These models have emerged in very different contexts and have several purposes. However, I believe that there are points of convergence that can be exploited to better understand the complexity of textual articulation. Based on the analysis of an introduction of a scientific paper, I notice that these models allow for complementary studies of textual articulation. As regards similarities, both the RST as MAM offer adequate analysis tools for studying the macrossintaxe of text. But each approach pays attention to certain aspects of textual articulation which, if taken into account by both approaches, would allow a more effective study of textual articulation.
\end{abstract}

Key words: Textual articulation. Rhetorical Structure Theory. Modular Approach of Discourse Analysis.

Recebido em: 14 de janeiro de 2014.

Aprovado em: 26 de setembro de 2014. 